\title{
Sero-epidemiology of Toxocara canis infection in people attending four educational and therapeutic centres in Alborz Province, Iran
}

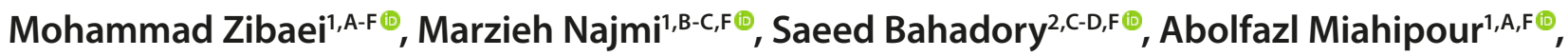 \\ Farzaneh Firoozeh ${ }^{3, C-D, F}$, Fatemeh Bakhshipour ${ }^{1, B, F} \oplus$ \\ ${ }^{1}$ Department of Parasitology and Mycology, School of Medicine, Alborz University of Medical Sciences, Karaj, Iran \\ ${ }^{2}$ Department of Parasitology, Faculty of Medical Sciences, Tarbiat Modares University, Tehran, Iran \\ ${ }^{3}$ Department of Microbiology, School of Medicine, Alborz University of Medical Sciences, Karaj, Iran \\ A - Research concept and design, B - Collection and/or assembly of data, C - Data analysis and interpretation, \\ $D$ - Writing the article, E - Critical revision of the article, F - Final approval of article
}

Zibaei M, Najmi M, Bahadory S, Miahipour A, Firoozeh F, Bakhshipour F. Seroepidemiology of Toxocara canis infection in people attending four educational and therapeutic centres in Alborz Province, Iran. Med Srod. 2021; 24(1-4): 25-29. doi: 10.26444/ms/144580

\begin{abstract}
Introduction and Objective. Toxocariasis is a common but neglected zoonotic disease caused by the larval stage of Toxocara species. The aim of this study is to highlight the sero-epidemiology of Toxocara canis infection in the general population of Alborz Province, Iran.

Materials and method. Anti-Toxocara canis antibodies were tested in 234 studied inhabitants by enzyme-linked immunosorbent assay (ELISA). Demographic characteristics and consent were obtained from each individual.

Results. In total, 33 (14.1\%) of the 234 participants (mean age 19.6 \pm 8.7 years) had anti-Toxocara canis antibodies. Prevalence of infection was higher in males (16.2\%) than females (12.4\%). High-titer antibodies were most prevalent among the subjects aged $\leq 20$ years, and showed statistical significance $(p=0.001)$. There was significant association between the presence of Toxocara antibodies and the place of residence, keeping dog at home, and contact with contaminated soils $(p<0.05)$. This is the first report of the sero-prevalence and contributing factors for Toxocara canis infection in the general population in Alborz Province.

Conclusions. These data confirm the importance of diagnosing human toxocariasis in this region. The findings, in addition to the hygienic status of the population, can be representative of the environmental and animal contamination. Necessary education to avoid contact with suspicious dog and non-contact with soil from infancy should be considered as preventive measures for Toxocara infection.
\end{abstract}

\section{Key words}

Toxocara canis, diagnosis, toxocariasis, sero-epidemiology, ELISA, Iran

\section{INTRODUCTION}

Toxocariasis is an important helminthic zoonosis due to the human infection by larvae of Toxocara canis (T. canis), the common nematode of dogs, and less frequently by the cat nematode Toxocara cati (T. cati) [1]. The human infection is acquired through the ingestion of embryonated eggs found in soil, contaminated vegetables, on dirty hands or undercooked meat of the paratenic hosts that hatch in the host's intestine [2]. There is a varied clinical spectrum of toxocariasis in humans, ranging from asymptomatic infection to severe organ injury, with symptoms related to the migration of third-stage larvae of Toxocara species via the bloodstream to the internal organs. The expatriation of parasitic larvae into the viscera or other organs causes the symptomatic form of infection, in the state situation manifestations include three major complications of visceral and ocular larvae migration, and neurotoxocariasis [3]. The majority of the population involved in Toxocara infection are children, but the detection

Address for correspondence: Mohammad Zibaei, Alborz University of Medical Sciences, Talaghani Square, North Talaghani Blvd, 3149779453, Karaj, Iran

E-mail: zibaeim@sums.ac.ir of even previous infections in adults is valuable because it not only determines the prevalence of infection in individuals in the area, but is also a good indicator for environmental health assessment, animal infection status, and from the preventive planning perspective [4].

Enzyme Linked Immunosorbent Assay (ELISA), although a relatively old technique, is still a highly sensitive and reliable test in the diagnosis of some infections, one of which is Toxocara. ELISA based on T. canis excretory-secretory (TcES) antigen is routinely used. TcES-ELISA sensitivity and specificity is estimated approximately $78 \%$ and $92 \%$ respectively $[5,6]$. To-date, most studies have included a specific population in evaluation of toxocariasis prevalence: in Iran, eosinophilia individuals under 14 years of age [7]. However, it should be noted that this is not always the case, and eosinophilia is not necessarily in all Toxocara infections, all age groups should also be included. Risk factors that may contribute to Toxocara infection should be considered in addition to age, gender, primarily exposure rate, and contact with contaminated soil and/or an infected animal, personal health situation; additionally, the economic and education status, as well as other demographic variables, should be included. 
This is the first sero-epidemiological study to be performed in this region, although Toxocara epidemiological research, including ocular toxocariasis, soil contamination by Toxocara spp., and paratenic hosts of $T$. canis have been carried out previously $[8,9]$.

\section{OBJECTIVE}

Due to the importance of this helminth zoonosis and lack of data about its prevalence in the studied area, a sero-epidemiological study was conducted with the aim of assessing the prevalence of human Toxocara infection, and the epidemiological factors associated with the spread of the disease.

\section{MATERIALS AND METHOD}

Ethical consideration. Informed consent was obtained from all participants. The study design, including its ethical aspects, was reviewed and approved by the Ethics Committee of Alborz University of Medical Sciences (IR.ABZUMS. REC.1398.107).

Study Area. Alborz Province centered in Karaj (35 49'57", $50^{\circ} 59^{\prime} 29^{\prime \prime}$ ), is located in the north of Iran (Fig. 1). This region with a population of around 3 million is one of the five most populous cities in Iran. The Alborz Province climate, to some extent, is cooler than the neighbouring provinces, with a mean temperature in this area of $15.1^{\circ} \mathrm{C}$, and an annual rainfall of $260 \mathrm{~mm}$ (https://en.wikipedia.org/wiki/Alborz_Province).

Serum samples. A total of 234 sera samples were collected from randomly examined individuals (129 females, 105 males) attending four educational and therapeutic centres in Alborz Province, Iran, between October 2020 - March 2021. Of the 234 people who gave blood samples, 141 lived in urban and 93 in rural areas. The demographic details of the respondents and data relating to their demographic characteristics, including age, gender, place of residence, occupation, history of disease, and level of education, were recorded. After consent was given by each participant, their demographic details and infection risk factors regarding gender, age, contact with of dogs and cats or their feces, income and education, as well as urbanization level, also were obtained. None of the participants had specific clinical signs of the disease.

TcES based Enzyme Linked Immunosorbent Assay. In the Parasitology Laboratory of the School of Medicine, Alborz University of Medical Sciences, peripheral venous blood samples $(\sim 5 \mathrm{~mL})$ were taken under sterile conditions from 234 randomly examined individuals, and the sera of these samples were separated by centrifuge at 2,500 rpm, aliquot, and stored at $-20^{\circ} \mathrm{C}$ until analyses were carried out. Anti-Toxocara antibodies were detected by commercial Enzyme-Linked Immunosorbent Assay (ELISA) kit (NovaTec Immunodiagnostica GmbH, Dietzenbach, Germany), according to the manufacture's instructions.

Statistical analysis. Statistical tests were performed to evaluate the association between study variables and results. Demographic characteristics and possible risk factors for Toxocara infection were assessed by Chi-square tests with a $95 \%$ confidence interval $(95 \% \mathrm{CI})$. All data analyses were carried out with SPSS 21.0 statistical software.

\section{RESULTS}

Of the 234 serum samples, 33 (14.1\%) people IgG against T. canis infection were tested positive by the TcES-ELISA kit. The distribution of the titers is shown in Table 1. Seroprevalence was higher in males - 16.2\% (17/105), than females $-12.4 \%$ (16/129), respectively (Tab. 2). The prevalence

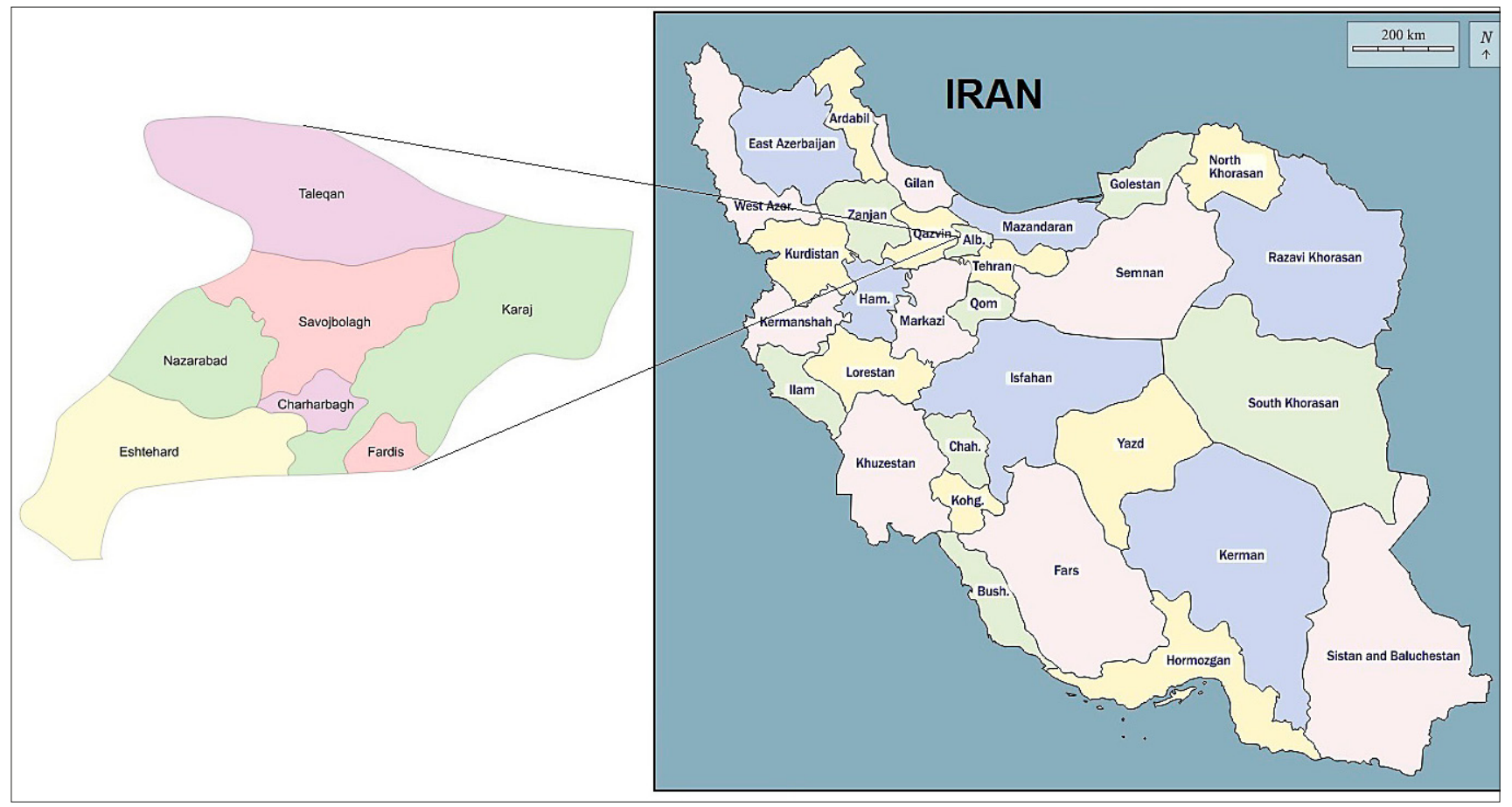

Figure 1. Location of studied sites 
Table 1. Distribution of Toxocara serologic titers by ELISA

\begin{tabular}{lcc}
\hline \multirow{2}{*}{ Serologic titers } & \multicolumn{2}{c}{ People } \\
\cline { 2 - 3 } & Number & Percent \\
\hline $1: 160$ & 3 & 1.3 \\
\hline $1: 320$ & 4 & 1.7 \\
\hline $1: 640$ & 22 & 9.4 \\
\hline $1: 1280$ & 3 & 1.3 \\
\hline Negative & 1 & 0.4 \\
\hline Total & 201 & 85.9 \\
\hline
\end{tabular}

Table 2. Characteristics of people investigated by enzyme-linked immunosorbent assay for human toxocariasis

\begin{tabular}{|c|c|c|c|c|}
\hline \multirow[b]{2}{*}{ Factors } & \multirow[b]{2}{*}{ Total } & \multicolumn{2}{|c|}{ Statistical analysis } & \multirow{2}{*}{$\begin{array}{c}(\mathrm{P} \\
\text { value }) \dagger\end{array}$} \\
\hline & & $\begin{array}{c}\text { Seropositive } \\
(\%)\end{array}$ & $\begin{array}{c}\text { Seronegative } \\
(\%)\end{array}$ & \\
\hline \multicolumn{5}{|l|}{ Age group (years) } \\
\hline Less than 20 & $76(32.4)$ & $17(22.4)$ & $59(77.6)$ & 0.001 \\
\hline $21-40$ & $66(28.2)$ & $10(15.2)$ & $56(84.8)$ & \\
\hline $41-60$ & $75(32.1)$ & $4(5.3)$ & $71(94.7)$ & \\
\hline More than 60 & $15(7.3)$ & $2(13.3)$ & $13(86.7)$ & \\
\hline \multicolumn{5}{|l|}{ Gender } \\
\hline Female & $129(55.1)$ & $16(12.4)$ & $113(87.6)$ & 0.746 \\
\hline Male & $105(44.9)$ & $17(16.2)$ & $88(83.8)$ & \\
\hline \multicolumn{5}{|l|}{ Soil contact } \\
\hline Yes & $82(35.1)$ & $21(25.6)$ & $61(74.4)$ & 0.049 \\
\hline No & $152(64.9)$ & $12(7.9)$ & $140(92.1)$ & \\
\hline \multicolumn{5}{|l|}{ Pet keeping } \\
\hline Yes & $32(13.7)$ & $9(28.1)$ & $23(71.9)$ & 0.031 \\
\hline No & $202(86.3)$ & $24(11.9)$ & $178(88.1)$ & \\
\hline \multicolumn{5}{|l|}{ Education } \\
\hline High school diploma & $222(94.9)$ & $18(8.1)$ & 204 (91.9) & 0.404 \\
\hline More than high school & $12(5.1)$ & $5(41.7)$ & $7(58.3)$ & \\
\hline \multicolumn{5}{|c|}{ Income threshold (monthly) } \\
\hline$\leq 2000$ & $116(49.6)$ & $17(14.7)$ & $99(85.3)$ & 0.629 \\
\hline 2001-3999 & $69(29.5)$ & $9(13.1)$ & $60(86.9)$ & \\
\hline$\geq 4000$ & 49 (20.9) & $3(6.1)$ & $46(93.9)$ & \\
\hline \multicolumn{5}{|l|}{ Residency } \\
\hline Urban & $141(60.3)$ & $12(85.7)$ & $2(14.3)$ & 0.024 \\
\hline Rural & 93 (39.7) & $2(2.1)$ & 91 (97.9) & \\
\hline
\end{tabular}

'Significance by the $x^{2}$ test; ${ }^{\ddagger}$ Dollars (US)

rate in the age group $\geq 60$ years was the lowest among the other age groups $7.3 \%$ (15/234); overall, the age factor was statistically significantly associated with infection $(\mathrm{p}=0.001)$, followed by contact with dogs $(\mathrm{p}=0.031)$ and soil $(\mathrm{p}=0.049)$ variables, respectively. On the other hand, among the studied variables and possible risk factors, was significantly associated with T. canis infection, but the rest of them, such as education and income level, as well as urbanization, were not significantly related to infection (Tab. 2).

Antibodies to T. canis were surveyed in 234 subjects aged 5-79 years (mean 19.6 \pm 8.7 years), with an overall seroprevalence rate of $14.1 \%$, which was substantially higher among those aged $\leq 20$ years $(n=17,22.4 \%)$ than in older subjects aged $21-40$ years $(n=10,15.2 \%, 41-60, n=4,5.3 \%)$, and $>60$ years $(n=2$, $11.8 \%$; $=0.001)$. High-titer antibodies were most prevalent among those in the age group $\leq 20$ years, suggesting that recent or current exposure to Toxocara is most common in this age group. Seropositivity was more prevalent in males (16.2\%) than in females (12.4\%), and showed no statistical significance $(\mathrm{p}=0.746)$. Some demographic characteristics, such as education, were not significantly associated with the presence of Toxocara antibodies in unadjusted analysis (Tab. 2).

\section{DISCUSSION}

Human toxocariasis is an important health problem in the developing countries. Immunodiagnostic tests against toxocariasis are valuable for compiling epidemiological data, and used as additional tools in clinical diagnosis to detect specific antibodies with great precision. The socioeconomically disadvantaged and demographic factors may lead to increase in Toxocara sero-prevalence which is widely recognized as a parasitic disease worldwide, and may be much more common than previously thought. Since the clinical symptoms of toxocariasis are of limited value in the differential diagnosis, serological tests are of considerable importance in the detection of Toxocara infection [5]. Most epidemiological studies on human toxocariasis in Iran have been carried out on children and the sero-prevalence ranged between $1.4 \%-29.5 \%$ [7].

To the best knowledge of the authors, the current study is one of the first to present serological data of T. canis infection among the population of the Karaj district in Iran. The frequency of Toxocara infection in people participating in the study was $14.1 \%$. A high sero-prevalence $(9.4 \%)$ was observed in 22 studied people with elevated antibodies titers of 1:640. The interpretation of sero-prevalence data remains very difficult due to the use of different cut-off titers by various researchers, and the difficulty in evaluating the relationship between titer level, infection, and clinical findings of the disease [10].

The prevalence of human Toxocara infection confirms that Karaj has a comparable infection rate with other areas in which toxocariasis is considered to be highly endemic. In a study by Zahedan in southeast Iran, $11.3 \%$ of the students with cough were seropositive [11]. A case control-study showned that the prevalence of toxocariasis and Toxocara antibodies was $14.7 \%$ among multiple sclerosis patients in Khorram Abad, southwest Iran [7]. The prevalence of Toxocara infection in the present study is similar to the rates reported in previous studies, although the rate of Toxocara infection in the present study was slightly lower than the rates in other countries, including Taiwan (57.5\%) [12], Philippines (49.0\%) [13] Korea (51.2\%) [14], and Thailand (58.2\%) [15], whereas the rate was higher than those in some other parts of the world, including Turkey (8.0\%) [16], and in the Czech Republic (3.6\%) [17].

Given that pet keeping was a putative risk factor, the findings of the current study showed that the highest seropositive individuals had been exposed to dog contaminated faeces (28.1\%), while the lowest incidence occurred with the lack of contact to dog faeces (11.9\%). However, human toxocariasis is an important and common zoonotic helminthes infection worldwide [2]. 
The current study shows that the seropositivity rate was not significantly higher in males (16.2\%) than females $(12.4 \%)$. The reasons for such a high prevalence could be attributed to different behavioural attitudes, and the close contact of males with their dogs. The results of the study provide an indication of the prevalence of toxocariasis among the subjects aged less than 20 years (22.4\%). According to a previous study, the prevalence of toxocariasis is in the age group of young children (Arefkhah et al., 2020). Several risk factors for toxocariasis have been identified in the human population, but inconsistent results are abundant. Gender, for example, was suggested to be associated with both increased and decreased risk of infection. Young age and poor sanitation are additional factors contributing to Toxocara exposure in some communities [19].

In the current study, similar to previous studies on Toxocara sero-prevalence [20], it was found that Toxocara seropositivity is higher in people with a lower income. The reasons for such a high prevalence could be attributed to different behavioural attitudes, lack of sanitation, malnutrition, and a low-quality of life associated with poor economic conditions. However, these associations were not statistically significant in the multivariate analysis.

A main finding of the study was the significant different to Toxocara between sero-prevalence in the rural population compared with the urban population, so that a significant difference was found between rural life and urban life $(22.6 \%$ vs. $7.5 \%$, respectively). The current study confirms that inhabitants of rural communities may be heavily exposed to Toxocara. The presence of an unrestrained dog population and adequate climate and environmental conditions for egg survival contribute to the high seroprevalence rate observed. Some researchers have found that the risk of developing Toxocara infection is higher in rural areas than in urban areas [19]. In earlier studies, some provinces in Iran, such as East Azerbaijan, Ahvaz, and Mashhad, demonstrated a significant difference with the place of living. It was observed that most of the affected people were in soil contact in rural areas [8].

An important result of the presented study is the high seropositivity rate (28.1\%) of toxocariasis in people who keep dogs, with the probable reason being the presence of dogs in the household and their close contact with Toxocara eggs.

The seropositivity rate was not affected by level of education, although there were significantly more seropositive patients who did not have college education. The high prevalence of antibodies titer in people with primary education may be associated with socio-economic status, an observation that suggests that the population with primary education were more likely to be exposed to the parasite.

It is worth mentioning that the current study has some limitations which constrained the findings: 1) the clinical and laboratory parameters were not fully investigated in all patients; 2) no correlations were shown between eosinophilia and toxocariasis, and 3) it seems likely that history taking for risk factors may had been incompletely performed; therefore, in future, thorough evaluation with laboratory parameters and history taking should be undertaken in cases where toxocariasis is suspected.

\section{CONCLUSIONS}

In spite of numerous studies conducted on this disease, evidence-based and standardized approaches are still needed to define appropriate strategies for the epidemiological evaluation, immunodiagnosis, and clinical management of Toxocara infection, among others.

\section{REFERENCES}

1. Magnaval JF, Glickman LT, Dorchies P, Morassin B. Highlights of human toxocariasis. Korean J Parasitol. 2001; 39(1): 1-11. http://doi. org/10.3347/kjp.2001.39.1.1

2. Despommier D. Toxocariasis: clinical aspects, epidemiology, medical ecology, and molecular aspects. Clin Microbiol Rev. 2003; 16 (2): $265-$ 272. http://doi.org/10.1128/cmr.16.2.265-272.2003

3.Zibaei M, Sadjjadi SM, Jahadi-Hosseini SH. Toxocara cati larvae in the eye of a child: a case report. Asian Pac J Trop Biomed. 2014; 4 (Supl 1): S53-S55. http://doi.org/10.12980/APJTB.4.2014C1281

4. Raissi V, Saber V, Zibaei M, Bahadory S, Akhlaghi E, Raeisi O, Aslani $\mathrm{R}$, Shamsi L, Graili A, Ibrahim A. Comparison of the prevalence of Toxocara spp. eggs in public parks soils in different seasons, from 2017 to 2018, Tehran Province, Iran. Clin Epidemiol Global Health. 2020; 4 (8): 450-454. https://doi.org/10.1016/j.cegh.2019.10.007

5. Smith H, Holland CV, Taylor M, Magnaval J, Schantz P, Maizels R. How common is human toxocariasis? Towards standardizing our knowledge. Trends Parasitol. 2009; 25(4): 182-188. http://doi.org/10.1016/j. pt.2009.01.006

6. Fu CJ, Chuang TW, Lin HS, Wu CH, Liu YC, Langinlur MK, et al. Seroepidemiology of Toxocara canis infection among primary schoolchildren in the capital area of the Republic of the Marshall Islands. BMC Infect Dis. 2014; 14 (1): 261. http://doi.org/10.1186/14712334-14-261

7. Eslahi AV, Badri M, Khorshidi A, Majidiani H, Hooshmand E, Hosseini $\mathrm{H}$, et al. Prevalence of Toxocara and Toxascaris infection among human and animals in Iran with meta-analysis approach. BMC Infect Dis. 2020; 20(1): 20. http://doi.org/10.1186/s12879-020-4759-8

8.Zibaei M, Bahadory S, Cardillo N, Khatami AR. Soil contamination with eggs of Toxocara species in public parks of Karaj, Iran. Int J Enteric Pathogs. 2017; 5 (2): 45-48. http://doi.org/10.15171/ijep.2017.11

9.Zibaei M Alemi, M, Cardillo NM, Derafshi H, Miahipour A, Bahadory, et al. Human toxocariasis seroprevalence among patients with uveitis in Alborz Province, Iran. Ann Agric Environ Med. 2019; 26(1): 154-158. http://doi.org/10.26444/aaem/102293

10. Holland CV, O'Lorcain P, Taylor MR, Kelly A. Seroepidemiology of toxocariasis in school children. Parasitology. 1995; 110(Pt5): 535-545. http://doi.org/10.1017/s0031182000065252

11. Ghorbani-Ranjbary A, Ghorbani-Ranjbary N, Varzandian S, GhorbaniRanjbary Z. Frequency of anti-Toxocara antibodies in students with chronic cough and eosinophilia in a rural Area of Shiraz, Iran. Zahedan J Res Med Sci. 2015; 17(1): 15-18. https://sites.kowsarpub.com/zjrms/ articles/1921.html

12. Fan CK, Liao CW, Kao TC, Li MH, Du WY, Su KE. Sero-epidemiology of Toxocara canis infection among aboriginal schoolchildren in the mountainous areas of northeastern Taiwan. Ann Trop Med Parasitol. 2005; 99(6), 593-600. http://doi.org/10.1179/136485905X51373

13. Fajutag AJ, Paller VG. Toxocara egg soil contamination and its seroprevalence among public school children in Los Banos, Laguna, Philippines. Southeast Asian J Trop Med Public Health. 2013; 44(4): 551560. https://www.tm.mahidol.ac.th/seameo/2013-44-4-full/02-5496-6. pdf.

14. Lee JY, Yang MH, Hwang JH, Kang M, Paeng JW, Yune S, et al. The prevalence of toxocariasis and diagnostic value of serologic tests in asymptomatic Korean adults. Allergy Asthma Immunol Res. 2015; 7(5): 467-475. http://doi.org/10.4168/aair.2015.7.5.467

15. Phasuk N, Punsawad C. Seroprevalence of Toxocara canis infection and associated risk factors among primary schoolchildren in rural Southern Thailand. Trop Med Health. 2020; 48(2): 23. http://doi.org/10.1186/ s41182-020-00211-0

16. Sozen H, Citil BE, Caylak S, Gokmen AA, Kaya S, Demirci M, et al. Seroepidemiological study of toxocariasis among volunteers animal husbandry workers and veterinary in southern Anatolia in Turkey in 2014. Iran J Parasitol. 2015; 10(3): 473-481. https://ijpa.tums.ac.ir/index. php/ijpa/article/view/314. 
17. Skulinova K, Novak J, Kasny M, Kolarova L. Seroprevalence of larval toxocarosis in the Czech 6Republic. Acta Parasitol. 2020; 65(1): 68-76. http://doi.org/10.2478/s11686-019-00121-0

18. Arefkhah N, Shadzi MR, Mikaeili F, Sarkari B, Esfandiari F, Goudarzi F. Seroprevalence and associated risk factors of toxocariasis among nomads in Boyer-Ahmad County, southwest Iran. Trans R Soc Trop Med Hyg. 2020: 114(5): 372-377. http://doi.org/10.1093/trstmh/trz117

19. Rezaiemanesh MR, Afzalaghaee M, Hamidi S, Eshaghzadeh A, Paydar M, Hejazi SH. Prevalence of toxocariasis and its related risk factors in humans, dogs and cats in northeastern Iran: a population-based study. Trans R Soc Trop Med Hyg. 2019: 113(7): 399-409. http://doi. org/10.1093/trstmh/trz011

20. Berrett AN, Erickson LD, Gale SD, Stone A, Brown BL, Hedges DW. Toxocara Seroprevalence and associated risk factors in the United States. Am J Trop Med Hyg. 2017; 97(6): 1846-1850. http://doi.org/10.4269/ ajtmh.17-0542 